\title{
Comparative evaluation of intravaginal slow release Dinoprostone insert, transcervical foley's catheter, intracervical Dinoprostone gel for induction of labor in patients with poor Bishop's score: a randomized control study
}

\author{
Taru Gupta, Ritu Singh*, Nupur Gupta, Sangeeta Gupta, Khushbu Singal
}

Department of Obstetrics and Gynecology, ESIC Hospital, Basaidarapur, New Delhi, India

Received: 05 January 2020

Accepted: 20 January 2020

\author{
*Correspondence: \\ Dr. Ritu Singh, \\ E-mail: ritzius1402@gmail.com
}

Copyright: $($ the author(s), publisher and licensee Medip Academy. This is an open-access article distributed under the terms of the Creative Commons Attribution Non-Commercial License, which permits unrestricted non-commercial use, distribution, and reproduction in any medium, provided the original work is properly cited.

\begin{abstract}
Background: Induction of labor is indicated when the continuation of pregnancy poses risk to the mother or fetus. A variety of mechanical and pharmacologic methods are available but the best method of labor induction still remains unknown, study aimed at comparing the efficacy and safety among the two agents: transcervical Foley's balloon catheter (FBC) and intravaginal slow release Dinoprostone E2 insert (DVI) with dinoprostone gel as control.

Methods: A total of 174 patients were randomized into three groups of 58 each (Group A: dinoprostone $10 \mathrm{mg}$ slow release intravaginal insert, Group B: transcervical Foley's 16 French catheters, and Group C as control: $0.5 \mathrm{mg}$ intracervical Dinoprostone gel. The safety and efficacy was compared among the groups. A p value of $<0.05$ was considered statistically significant.

Results: The mean insertion to active labor time (in hours) was significantly lower in Group A as compared to Group B $(5.88 \pm 3.06$ versus $13.56 \pm 2.8, \mathrm{p}<0.0001)$. Meantime of insertion to delivery (in hours) was significantly lower in Group A as compared to Group B $(10.91 \pm 5.24$ versus $21.17 \pm 2.99$, p < 0.0001). The requirement of oxytocin for induction and augmentation in Group A was significantly lower as compared to Group B. Majority of the patients had normal vaginal delivery (NVD) in all the three groups. Regarding safety profile we found that slow-release DVI had more incidence of uterine tachysystole, but none of the cases had any fetal heart rate abnormality. Maternal fever was more in the FBC group, however, neonatal outcomes were comparable in both groups.

Conclusions: The study concludes that slow release DVI is better in terms of efficacy as compared to transcervical FBC for induction of labor as assessed by improvement in Bishop score, insertion to active labor time and insertion to delivery time and comparable in terms of safety profile.
\end{abstract}

Keywords: Bishop's score, Dinoprostone insert, Foley's catheter, Induction of labor, Intravaginal, Transcervical

\section{INTRODUCTION}

The condition of the cervix-described as cervical "ripeness" or "favorability"-is important to successful labor induction. ${ }^{1}$ Goal of cervical ripening is to facilitate the cervical softening, thinning and dilating with resultant reduction in failed induction. ${ }^{2}$ Pharmacological preparations are in widespread use for cervical ripening but are not free from side-effects and complications. ${ }^{3}$ Mechanical methods, i.e. the use of Foley catheter balloon, though effective have not gained much popularity because of the fear of infection. Success in labor induction primarily depends on the cervical status at the time of induction. Patients with a poor Bishop score 
(<6) will have an unacceptably high rate of induction failure. A variety of methods, including mechanical and pharmacologic methods, are available for cervical ripening. Mechanical method like Foley's balloon catheter (FBC) mainly work by physically dilating the cervix and stimulating the release of endogenous prostaglandins. Pharmacologic ripening agents include exogenous prostaglandin can be administered orally, vaginally or intra-cervically. Currently, prostaglandin E2 preparations such as intravaginal slow release Dinoprostone insert (DVI) are the preferred choices in many countries. However, the best method of labor induction still remains unknown. ${ }^{4}$ Prostaglandin E2 preparations should only be administered in or near the delivery suite. Moreover, uterine activity and fetal heart rate should be monitored (American College of obstetricians and gynecologists, 2013b). These guidelines stem from the risk of uterine tachysystole.

\section{METHODS}

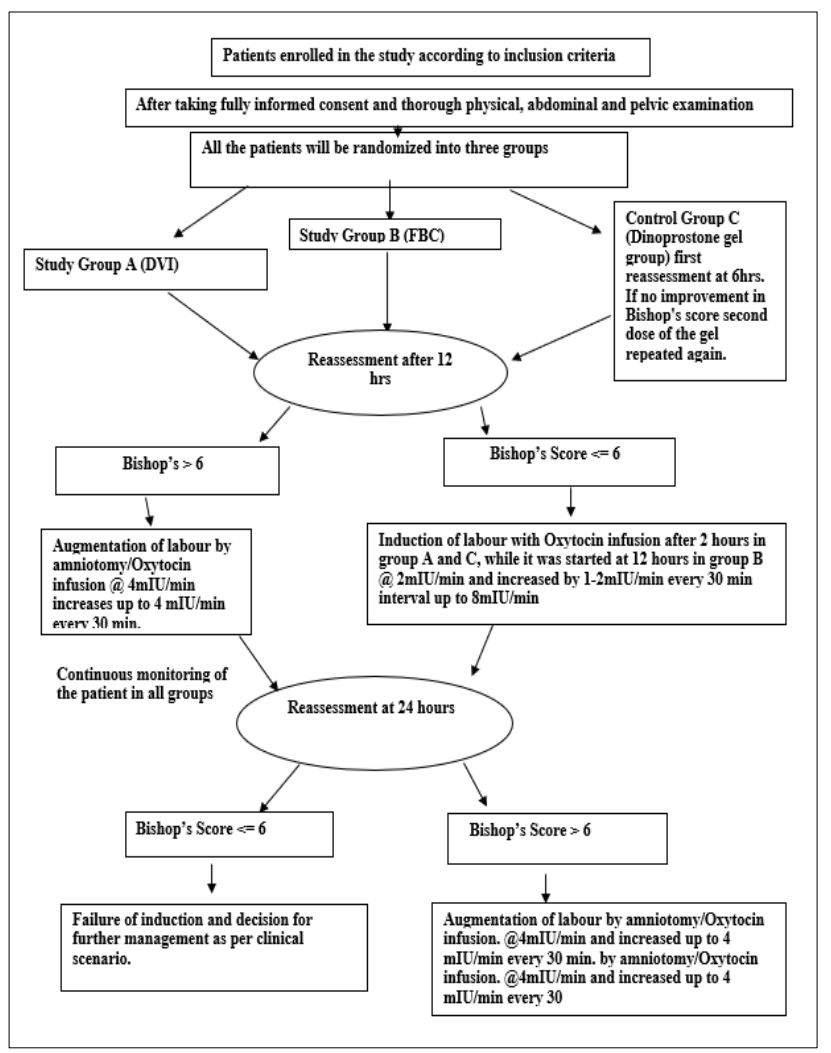

Figure 1: Labour induction in 3 randomized group: [Dinoprostone slow release intravaginal insert Group (A) and Foley's catheter Group (B) and Dinoprostone gel Group (C)].

A prospective randomized control study was done from September 2017 to February 2019 in the labour ward at ESI PGIMSR Delhi. A total of 174 patients were randomized into three groups:

- Study Group A: $(\mathrm{n}=58)$ were induced by Dinoprostone $10 \mathrm{mg}$ slow release intravaginal insert.
- Study Group B: $(\mathrm{n}=58)$ were induced through transcervical Foley's 16 French catheters.

- Study Group C: $(\mathrm{n}=58)$ were induced with $0.5 \mathrm{mg}$ intracervical Dinoprostone gel.

\section{Inclusion criteria}

Maternal age greater than 18 years, singleton pregnancy, cephalic presentation, reactive FHR, intact membranes, Bishop's score less than 6, no contraindications to vaginal delivery and where induction of labor was required - post-term pregnancy, mild pre- eclampsia, diabetes mellitus, intrauterine growth restriction, IHCP, chronic hypertension in mother, gestational hypertension.

\section{Exclusion criteria}

Previous uterine and cervical surgery, estimated fetal weight greater than 4500 gms or less than 1500 gms, APH, CPD, Moderate to severe preeclampsia, Glaucoma, any contraindications or hypersensitivity to prostaglandins, grand multipara. Women meeting the inclusion criteria were enrolled and an informed consent was obtained. Patients were randomized by the sealed envelope method, described in flow chart below. ${ }^{1}$

\section{Outcome measures}

Primary outcome were assessment of induction to active labour time, induction to delivery time. Secondary outcome were requirement of oxytocin, mode of delivery, uterine contraction abnormalities, Apgar score at 1 and 5 minutes, any maternal complication and duration of stay in hospital.

\section{Statistical analysis}

Categorical variables were presented in number and percentage (\%) and continuous variables were presented as mean \pm SD and median. Normality of data was tested by Kolmogorov- Smirnov test. Statistical tests were applied with respect to, quantitative variables were compared between the two groups and ANOVA test between three groups. Secondly, qualitative variables were correlated. A p value of $<0.05$ was considered statistically significant. The data was entered in MS Excel spreadsheet and analysis was done using Statistical Package for Social Sciences (SPSS) version 21.0.

\section{RESULTS}

The mean age of the patients in Group A was 26.17 \pm 4.01 years; in the Group, B was 26.38 \pm 3.07 years and in Group C was $26.31 \pm 4.06$ years and were comparable. Most of the patient in Group A and B were second gravida. The mean gestational age in Group A was $39.26 \pm 1.25$ weeks; in the Group B was $39.09 \pm 1.08$ weeks and in Group $\mathrm{C}$ was $39.19 \pm 1.16$ weeks. The most common indication for induction in all three groups was postdatism pregnancy $(41.95 \%)$ followed by 
preeclampsia $(16.67 \%)$ and intrahepatic cholestasis of pregnancy IHCP (16.67\%) (Table 1).

Mean Bishop's score at 12 hours was comparable in Group A $(7.8 \pm 1.32$ versus $7.78 \pm 1.54, \mathrm{p}=0.473)$ and Group B $(7.33 \pm 1.73$ versus $7.78 \pm 1.54, p=0.96)$. It was comparable in all the groups, however, induction to delivery time in Group A and C was shorter. In Group A and C, $23(39.65 \%)$ and $26(44.82 \%)$ participants respectively delivered before 12 hours. The mean insertion to active labour time (in hours) was significantly lower in Group A as compared to Group B $(5.88 \pm 3.06$ versus $13.56 \pm 2.8, \mathrm{p}<0.0001)$. Meantime of insertion to delivery (in hours) was significantly lower in Group A as compared to Group B $(10.91 \pm 5.24$ versus $21.17 \pm 2.99$, p $<0.0001$ ) (Figure 2).

Table 1: Comparison of indication of induction between three groups.

\begin{tabular}{|c|c|c|c|c|c|c|c|c|}
\hline \multirow{2}{*}{ Indication for IOL } & \multicolumn{3}{|l|}{ Group } & \multirow{2}{*}{$\begin{array}{l}\text { Total } \\
(\mathrm{n}=174)\end{array}$} & \multirow{2}{*}{$\begin{array}{l}\mathbf{p} \\
\text { value }\end{array}$} & \multirow{2}{*}{$\begin{array}{l}\text { A vs } \\
\text { B }\end{array}$} & \multirow{2}{*}{ A vs $\mathbf{C}$} & \multirow{2}{*}{$\begin{array}{l}\text { B vs } \\
\text { C }\end{array}$} \\
\hline & $A(n=58)$ & $B(n=58)$ & $C(n=58)$ & & & & & \\
\hline $\begin{array}{l}\text { Decrease fetal } \\
\text { movement }\end{array}$ & $3(5.17 \%)$ & $6(10.34 \%)$ & $4(6.90 \%)$ & $13(7.47 \%)$ & \multirow{10}{*}{$<.0001$} & \multirow{10}{*}{0.024} & \multirow{10}{*}{$<.0001$} & \multirow{10}{*}{$<.0001$} \\
\hline $\begin{array}{l}\text { Fetal growth } \\
\text { restriction }\end{array}$ & $2(3.45 \%)$ & $3(5.17 \%)$ & $0(0.00 \%)$ & $5(2.87 \%)$ & & & & \\
\hline $\begin{array}{l}\text { Gestational } \\
\text { diabetes mellitus }\end{array}$ & $1(1.72 \%)$ & $7(12.07 \%)$ & $6(10.34 \%)$ & $14(8.05 \%)$ & & & & \\
\hline Hypothyroidism & $0(0.00 \%)$ & $3(5.17 \%)$ & $0(0.00 \%)$ & $3(1.72 \%)$ & & & & \\
\hline IHCP & $10(17.24 \%)$ & $8(13.79 \%)$ & $11(18.97 \%)$ & $29(16.67 \%)$ & & & & \\
\hline Preclampsia & $7(12.07 \%)$ & $0(0.00 \%)$ & $22(37.93 \%)$ & $29(16.67 \%)$ & & & & \\
\hline Oligohydramnios & $1(1.72 \%)$ & $1(1.72 \%)$ & $5(8.62 \%)$ & $7(4.02 \%)$ & & & & \\
\hline Postdated pregnancy & $34(58.62 \%)$ & $30(51.72 \%)$ & $9(15.52 \%)$ & $73(41.95 \%)$ & & & & \\
\hline Seizure disorder & $0(0.00 \%)$ & $0(0.00 \%)$ & $1(1.72 \%)$ & $1(0.57 \%)$ & & & & \\
\hline Total & $58(100 \%)$ & $58(100 \%)$ & $58(100 \%)$ & $174(100 \%)$ & & & & \\
\hline
\end{tabular}

Table 2: Comparison of mode of delivery between three groups.

\begin{tabular}{|c|c|c|c|c|c|c|c|c|}
\hline \multirow{2}{*}{$\begin{array}{l}\text { Mode of } \\
\text { delivery }\end{array}$} & \multicolumn{3}{|l|}{ Group } & \multirow{2}{*}{ Total $(\mathrm{n}=174)$} & \multirow{2}{*}{ p value } & \multirow{2}{*}{ A vs B } & \multirow{2}{*}{ A vs $\mathbf{C}$} & \multirow{2}{*}{$B$ vs $C$} \\
\hline & $A(n=58)$ & $B(n=58)$ & $C(n=58)$ & & & & & \\
\hline NVD & $45(77.59 \%)$ & $34(58.62 \%)$ & $41(70.69 \%)$ & $120(68.97 \%)$ & \multirow{5}{*}{0.460} & \multirow{5}{*}{0.162} & \multirow{5}{*}{0.695} & \multirow{5}{*}{0.561} \\
\hline Forceps & $3(5.17 \%)$ & $4(6.90 \%)$ & $2(3.45 \%)$ & $9(5.17 \%)$ & & & & \\
\hline Ventose & $1(1.72 \%)$ & $3(5.17 \%)$ & $2(3.45 \%)$ & $6(3.45 \%)$ & & & & \\
\hline $\begin{array}{l}\text { Caesarean } \\
\text { section }\end{array}$ & $9(15.52 \%)$ & $17(29.31 \%)$ & $13(22.41 \%)$ & $39(22.41 \%)$ & & & & \\
\hline Total & $58(100.00 \%)$ & $58(100.00 \%)$ & $58(100.00 \%)$ & $174(100.00 \%)$ & & & & \\
\hline
\end{tabular}

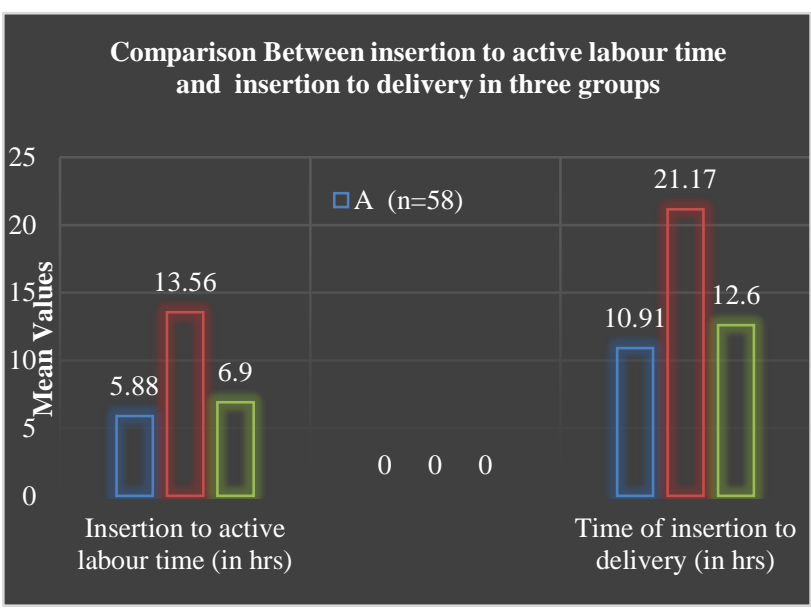

Figure 2: Depicting insertion to active labour time and insertion to delivery in the three groups.

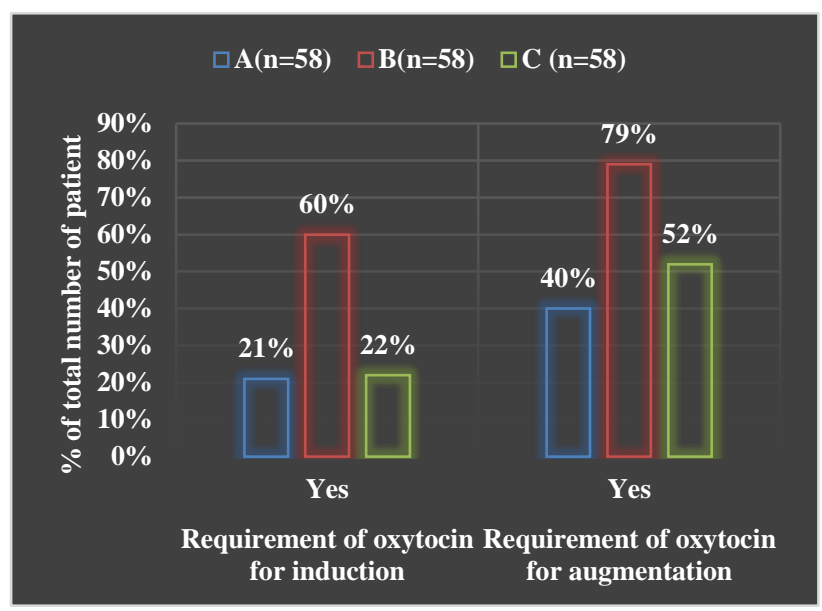

Figure 3: Comparison between requirement of oxytocin for induction and for augmentation of labour in the three groups. 
The requirement of oxytocin for induction in Group A was significantly lower as compared to Group B $(20.69 \%$ versus $60.34 \%, p<.0001)$. The requirement of oxytocin for augmentation in Group A was comparatively lower as compared to Group B $(39.65 \%$ versus $79.31 \%, p=0.041)$ (Figure 3). Among the study groups, failed induction was significantly more in Group B (13.79\% versus $1.72 \%, \mathrm{p}=$ 0.032).

Majority of the patients had normal vaginal delivery (NVD) in all the three Groups A, B and C [45 (77.59\%), $34(58.62 \%), 41(70.69 \%)$ followed by caesarean section [9 (15.52\%), 17 (29.31\%), 13 (22.41\%)] (Table 2). Mode of delivery was comparable among all the three groups $(\mathrm{p}$ $>0.05)$. Most common indication for C-section in Group A was meconium stained liqour with fetal distress $(44.44 \%)$, while in Group B, failed induction (47.06\%) and in Group C, fetal distress (46.15\%) was noted.

Among the study Groups A and B, uterine tachysystole was significantly more in Group A $(15.52 \%$ versus $0.00 \%, \mathrm{p}=0.003)$. However, there were no fetal heart rate abnormalities and all of them managed conservatively. Most of the incidence of uterine tachysystole was observed in 2 to 3 hours post insertion of inducing agent in - Group A and C. In Group A at diagnosis of uterine tachysystole vaginal pessary was removed immediately from posterior fornix of the vagina. The tachysystole could be because Dinoprostone causes increase in the intercellular calcium level causing contraction of myometrium tissue. In Group A maternal adverse effects observed were vomiting (10\%) and fever (5\%); Group B patients had fever (24\%), Group C had vomiting (9\%), postpartum haemorrhage $(7 \%)$, fever $(5 \%)$ and nausea $(2 \%)$. As compared to the control Group, mean Apgar score at 1 minute in Group A was lower $(7.79 \pm 0.83$ versus $6.67 \pm 0.78, p=0.0001)$ and in Group B it was comparable $(7.79 \pm 0.83$ versus $7.47 \pm 0.71$, $\mathrm{p}=0.0001)$. Mean Apgar score at 1 minute was lower in study Group A as compared to Group B (6.67 \pm 0.78 versus $7.47 \pm 0.71, p=0.024)$. Mean Apgar score at 5 minutes was comparable in study Groups $\mathrm{A}$ and $\mathrm{B}$ $(7.74 \pm 0.78$ versus $7.47 \pm 0.71, p=0.0241)$ and was lower than control Group C $(8.41 \pm 0.5)$. As compared to control Group C, mean duration of stay of mother and baby (days) in Group A was significantly lower (3.98 \pm 2.25 versus $5 \pm 2.27, \mathrm{p}=0.005)$; as compared to Group $\mathrm{B}$ $(7.21 \pm 1.76$ versus $5 \pm 2.27, \mathrm{p}<0.0001)$.

\section{DISCUSSION}

The mean age of patients in our study was 26.29 \pm 0.7 years. $59.19 \%$ of study participants were second gravida. The mean gestational age was 39.18 \pm 1.16 . Similar baseline characteristic were observed in the study. ${ }^{5-7}$ In an open-label, randomized controlled trial "Foley catheter versus vaginal prostaglandin E2 gel for induction of labor at term (PROBAAT trial): an open-label, randomized controlled trial" also found that median time from start of induction of labor to birth was longer with Foley's catheter as compared to intravaginal prostaglandins gel.

In our study, mean insertion to active labor time was significantly lower with DVI compared to FBC $(5.88 \pm 3.06$ versus $13.56 \pm 2.8, \mathrm{p}<0.0001)$. Even the mean insertion to delivery time was significantly lower with DVI compared to FBC $(10.91 \pm 5.24$ versus $21.17 \pm 2.99$, p $<.0001){ }^{8}$ In a systematic review found no significant difference between the 2 groups regarding the inductionto-delivery (I-D) interval (mean difference, 0.71 hours; $p$ $=0.67) . .^{5}$ on the other hand, found that induction to delivery time with Foley's catheter was lesser as compared to the Dinoprostone induction group (17.5 versus 24.4 hours, $\mathrm{p}<0.05)$.

The requirement of oxytocin for induction and augmentation in the study was significantly lower with DVI as compared to FBC. $^{5}$ Also had a similar observation in FBC versus Dinoprostone group $(88.6 \%$ versus $54.6 \% \mathrm{p}<0.001)$. Majority of the patients had normal vaginal delivery (NVD) in all the three groups. Our findings corroborated with various other studies. ${ }^{5}$ found a statistically non-significant lower rate of caesarean section in the FCB compared to the Dinoprostone induction group (11.3\% versus $17.3 \%$; $\mathrm{p}=$ $0.13)$; also showed no difference in caesarean section rate $(39.1 \%$ in each group; $\mathrm{p}=0.96){ }^{6}$ (RR, 0.94; 95\% CI, 0.80-1.21). ${ }^{9,10}$ Conducted a meta-analysis and concluded that there was a comparable incidence of caesarean deliveries with both Foley's and Dinoprostone insert.

In our study, maternal adverse effect was significantly different in the study groups $(\mathrm{p}=0.0007)$. In Group A maternal adverse effects observed were vomiting (10\%) and fever (5\%); Group B patients had fever (24\%), Group $\mathrm{C}$ had vomiting (9\%), postpartum hemorrhage (7\%), fever $(5 \%)$ and nausea $(2 \%)$. There was no maternal mortality. No patient required blood transfusion. ${ }^{9}$

Analyzed 26 randomized trial including 5,563 women and concluded both the group had similar rates of adverse effects; chorioamnionitis (7.2\% with Foley compared with $7.2 \%$ with prostaglandins; endometritis $(3.8 \%$ with FBC compared with $3.5 \%$ with DVI; pooled maternal infection (8.8\% with FBC compared with 9\%; and neonatal infection (3.2\% FBC compared with $3.6 \%$ DVI). They concluded that FBC was not associated with increased maternal and neonatal infection rate. ${ }^{8,10}$ Also found no significant difference between the 2 methods regarding side effects such as maternal infection rate, postpartum hemorrhage, and hyper stimulation.

In the study, uterine tachysystole was significantly more with DVI as compared to FBC (15.52\% versus $0.00 \%, \mathrm{p}$ $=0.003$ ) but there were no fetal heart rate abnormalities and all of them were managed conservatively. In contrast found no significant difference between the 2 methods regarding uterine hyperstimulation. ${ }^{8}$ 
We found that Apgar score at 5 minutes were comparable among the patients induced with Dinoprostone insert or Foley's catheter. ${ }^{10}$ Also observed no significant differences between the two groups regarding neonatal outcomes. $^{8}$ In his systematic review and found comparable neonatal outcomes with average scores more than 7 after five minutes. ${ }^{5,9}$

As the mean induction to delivery time and the mean duration of stay of mother was significantly lower with intravaginal Dinoprostone insert as compared to transcervical Foley's catheter, the study found that slow release intravaginal Dinoprostone insert had better efficacy than transcervical Foley's catheter with almost comparable safety profile.

\section{CONCLUSION}

The efficacy and safety are equally important factors when evaluating a cervical ripening method. This study concludes that intravaginal slow-release Dinoprostone PGE2 insert is better in terms of efficacy as assessed by improvement in Bishop's score, insertion to active labor time and insertion to delivery time. Regarding safety profile, intravaginal slow-release Dinoprostone PGE2 insert had more incidence of uterine tachysystole, but none of the cases had any fetal heart rate abnormality. Maternal adverse effects were more in the foleys catheter group, however, neonatal outcomes were comparable in both groups.

Funding: No funding sources Conflict of interest: None declared

Ethical approval: The study was approved by the Institutional Ethics Committee

\section{REFERENCES}

1. Cunningham FG. Williams obstetrics (24 ${ }^{\text {th }}$ ed.). New York: McGraw-Hill Education; 2014:525.

2. ACOG Practice Bulletin No. 107: Induction of labor. ACOG Committe on Practice Bulletins - Obstetrics. Obstet Gynecol. 2009;114:386-97.

3. Dalui R, Suri V, Ray P, Gupta L. Comparison of extra amniotic Foley catheter and intracervical prostaglandin $\mathrm{E}$ gel for preinduction cervical ripening. Acta Obstetricia et Gynecologica Scandinavica. 2005;84:362-7.

4. Cunningham FG. Williams obstetrics (24 $4^{\text {th }}$ ed.). New York: McGraw-Hill Education; 2014:527.

5. Ba Barda G, Ganer Herman H, Sagiv R, Bar J. Foley catheter versus intravaginal prostaglandins E2 for cervical ripening in women at term with an unfavorable cervix: a randomized controlled trial. The J Maternal-Fetal Neonat Med. 2018;31(20):2777-81.

6. Grange J, Dimet J, Vital M, Le Thuaut A, Ducarme G. Balloon catheter compared to vaginal dinoprostone for cervical ripening in obese women at term. Gynécologie, Obstétrique Fertilitý Amp; Sénologie. 2017;45(10):521-7.

7. Jozwiak M, Rengerink KO, Benthem M, Van Beek E, Dijksterhuis MG, De Graaf IM, et al. Foley catheter versus vaginal prostaglandin E2 gel for induction of labour at term (PROBAAT trial): an open-label, randomised controlled trial. The Lancet. 2011;378(9809):2095-103.

8. Zhu L, Zhang C, Cao F, Liu Q, Xing Gu, Xu J, et al. Intracervical Foley catheter balloon versus dinoprostone insert for induction cervical ripening: A systematic review and meta-analysis of randomized controlled trials. Medicine (Baltimore). 2018;97(48):e13251.

9. McMaster K, Sanchez-Ramos L, Kaunitz AM. Evaluation of a transcervical Foley catheter as a source of infection: a systematic review and metaanalysis. J Obstet Gynecol. 2015;126:539-51.

10. Wang $\mathrm{H}$, Hong $\mathrm{S}$, Liu $\mathrm{Y}$, Duan $\mathrm{Y}$, Yin $\mathrm{H}$. Controlled-release dinoprostone insert versus Foley catheter for labor induction: a meta-analysis. The J Maternal-Fetal Neonatal Med. 2016;29(14):2382-8.

Cite this article as: Gupta T, Singh R, Gupta N, Gupta S, Singal K. Comparative evaluation of intravaginal slow release Dinoprostone insert, transcervical foley's catheter, intracervical Dinoprostone gel for induction of labor in patients with poor Bishop's score: a randomized control study. Int J Reprod Contracept Obstet Gynecol 2020;9:932-6. 